\title{
STATOR RESISTANCE ESTIMATION FOR SPEED SENSORLESS VECTOR CONTROLLED INDUCTION MOTOR DRIVES AS INFLUENCED BY SATURATION
}

\author{
Yehia S. Mohamed, A. M. El-Sawy and A. A. Zaki \\ Electrical Engineering Department, Faculty of Engineering, Minia University, \\ EL-Minia, Egypt
}

(Received April 4, 2009 Accepted May 9, 2009)

\begin{abstract}
In this paper, stator resistance estimation for a speed sensorless vector controlled induction motor drive taking saturation into account is presented. A mathematical dynamic model of an induction motor as influenced by magnetic circuit saturation is presented. Moreover, a modified structure of indirect vector controller scheme is proposed which involves the saturated value of the magnetizing inductance. Parallel stator resistance and rotor speed estimation based on model reference adaptive system (MRAS) has been used to obtain accurate estimation for rotor speed. On-line magnetizing inductance estimation has been used within the speed estimator. Digital simulations have been carried out in order to evaluate the effectiveness of the proposed sensorless drive system. The results prove excellent steady-state and dynamic performances of the drive system in a wide speed range, which confirms validity of the proposed scheme.
\end{abstract}

\section{1- INTRODUCTION}

Indirect field oriented controlled induction motor drives are increasingly used in highperformance drive systems. Accurate knowledge of stator resistance is not required in indirect field oriented control scheme [1]. Speed sensorless control of induction motor drives received great attention to avoid the different problems associated with direct speed sensors. A vast majority of speed estimation schemes rely on utilization of an induction motor model in the process of speed estimation [5] and require an accurate knowledge of all (or the most of) the motor parameters, including the stator resistance and magnetizing inductance.

So, the interest in stator resistance adaptation appeared recently, with the advances of speed sensorless systems [2]. An accurate value of the stator resistance is of crucial importance for correct operation of a sensorless drive in the low speed region, since any mismatch between the actual value and the set value used within the model of speed estimation may lead not only to a substantial speed estimation error but to instability as well [6]-[7]. Therefore, there is a great interest in the research community to develop online stator resistance identification schemes for accurate speed estimation in the low speed region.

The available online stator resistance identification schemes can be classified into a couple of distinct categories. All these methods rely on stator current measurement and chiefly require information regarding stator voltages [1]. 


\section{LIST OF SYMBOLS}

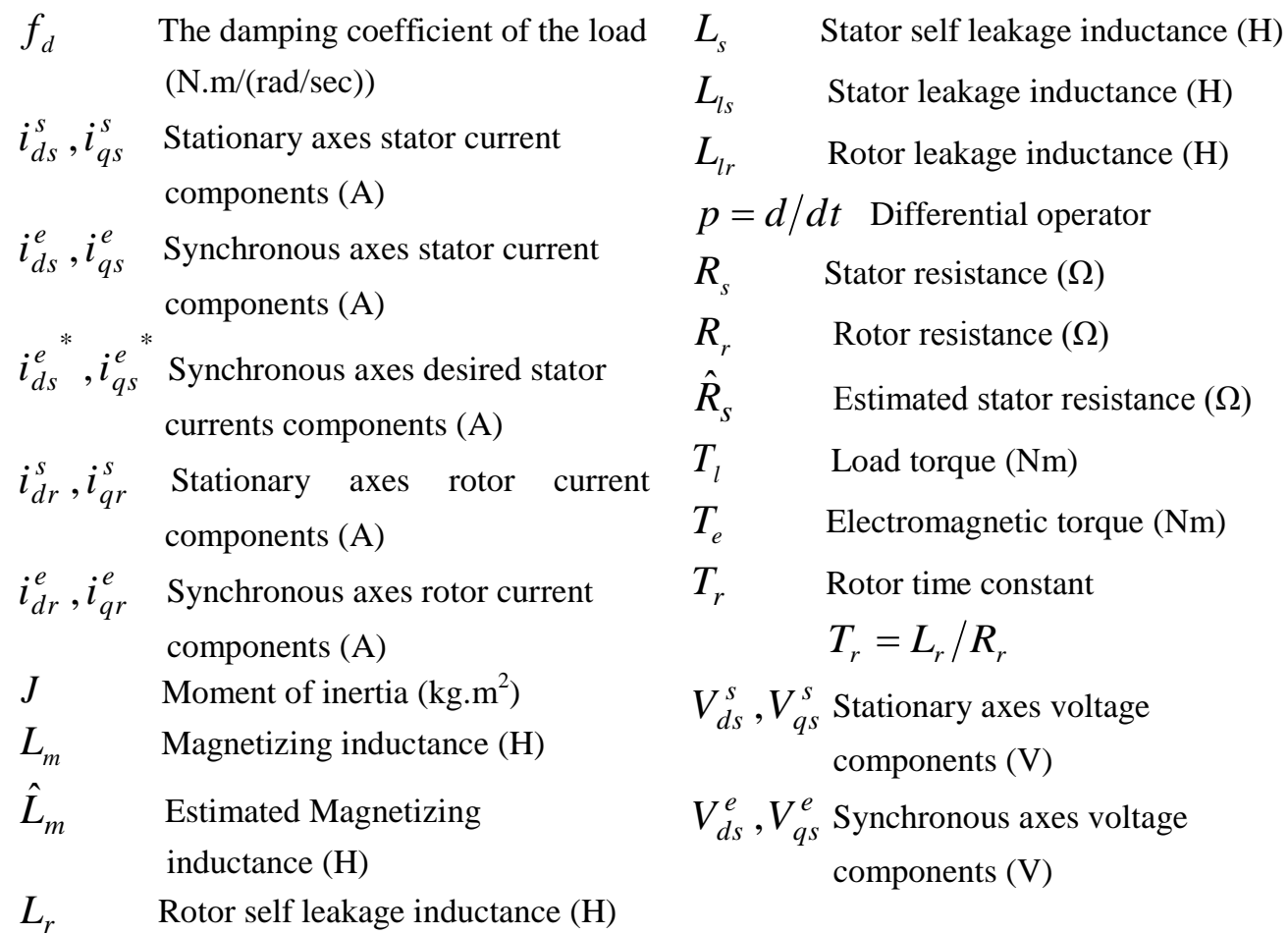

\section{Symbols}

$\vec{\lambda}_{r}^{s} \quad$ Rotor flux vector (wb)

$\theta_{e} \quad$ Angle between synchronous

$\lambda_{d r}^{s}, \lambda_{q r}^{s}$ Stationary axes rotor flux

components (wb)

$\lambda_{d r}^{e}, \lambda_{q r}^{e}$ Synchronous axes rotor flux

components (wb)

$\hat{\lambda}_{d r}^{s}, \hat{\lambda}_{q r}^{s}$ Stationary axes estimated rotor

flux components (wb)

$\lambda_{d m}^{s}, \lambda_{q m}^{s}$ Stationary axes magnetizing

flux components (wb)

$\lambda_{m} \quad$ Magnitude of magnetizing flux vector (wb) frame and stationary frame

$\omega_{e}^{*} \quad$ Command synchronous speed $(\mathrm{rad} / \mathrm{sec})$

$\omega_{e} \quad$ Synchronous speed $(\mathrm{rad} / \mathrm{sec})$

$\omega_{s l} \quad$ Slip speed $(\mathrm{rad} / \mathrm{sec})$

$\omega_{s l}^{*} \quad$ Command slip speed $(\mathrm{rad} / \mathrm{sec})$

$\omega_{r} \quad$ Actual Rotor speed $(\mathrm{rad} / \mathrm{sec})$

$\omega_{r}^{*} \quad$ Reference Rotor speed ( $\left.\mathrm{rad} / \mathrm{sec}\right)$

$\hat{\omega}_{r} \quad$ Estimated Rotor speed $(\mathrm{rad} / \mathrm{sec})$

$\sigma \quad$ Leakage coefficient $\left(1-L_{m}^{2} / L_{s} L_{r}\right)$

The most famous methods include different types of estimators which often use an adaptive mechanism to update the value of stator resistance [1]-[4]. The stator resistance is determined in [3] by using a reactive power based model reference adaptive system (MRAS). The reactive power relies on the accuracy of other parameters such as leakage inductance and rotor resistance which are not necessarily 
constant and the result is prone to error. Adaptive full-order flux observers (AFFO) for estimating the speed and stator resistance are developed using Popov's and Lyapunov stability criteria [4]. While this scheme is not computationally intensive, an AFFO with a non-zero gain matrix may become unstable. Model reference adaptive system for estimating the speed and stator resistance is developed using Popov's stability criterion [1]. In such method, the stator resistance adaptation mechanism is determined with the difference between the measured and observed stator currents. In [2], speed estimation with stator resistance algorithm based on a sliding mode current observer which combines variable structure control, Lyapunov stability and Popov's hyper stability theories are used. All of these methods assumed that there is no change in the magnetizing inductance during the stator resistance estimation. So the accuracy of these methods has been affected by the variation of the magnetizing inductance, if the magnetic circuit of the induction motor has been saturated. Also, these schemes cannot be used when the rotor speed is higher than the rated speed as in the field weakening region.

Many reasons cause variation in the level of the magnetic flux in the induction machine. From these reasons, induction motor has been saturated to produce higher torque and that causes a variation in the magnetizing inductance value and detuned in operation of vector control system. Also, if the field oriented induction motor drive operates in the base speed region with constant rated rotor flux reference; magnetizing inductance can be regarded as constant and equal to its rated value. But if the vector control drives operate in the field weakening region with speeds higher than the rated value and the rotor flux reference has to be reduced below its rated value, the assumption of the constant magnetizing inductance causes detuned in operation of the vector control system. Another reason, to obtain high dynamic performance of the drive system, it is necessary to keep the magnetizing current at the maximum level. At this level, modern machines are saturated. Most types of vector control systems are sensitive to errors resulting from non-constant parameters and furthermore, do not give an accurate representation of the machine under saturated magnetic conditions. Also, the optimal operation of an induction machine under field-oriented control basically involves the proper selection of the flux level to meet the optimal requirements of the specific applications. It has been emphasized that the influence of saturation on the selection of this flux is very significant and must be incorporated in the selection process to obtain valid and useful results. If the magnetizing flux is not constant (e.g. field-weakening, optimal operation, incorrect flux control; etc) it is also necessary to incorporate the effect of saturation in the overall control system. Many methods attempt to estimate the magnetizing inductance. Reference [12] suggests a method for tuning the magnetizing inductance but this method uses eather the speed sensors or it suffers from decoupling problems with the rotor speed. Another method used in [8]-[9] depends on measured stator voltages and currents and the magnetizing curve of the machine and this method is characterized with its simplicity. The saturation effect in the indirect vector control of induction motor has been investigated/compensated by authors [13]-[14]. In these methods, the performance of vector controlled induction motor drives as influenced by magnetic saturation and its compensation has been investigated but using speed sensor. On the other hand, no attempt has been made to investigate the effect of magnetic saturation on the performance of stator resistance estimation for sensorless indirect vector controlled induction motor drives. 
In this paper, the stator resistance identification for a speed sensorless vector controlled induction motor drives taking saturation into account has been presented. Mathematical models of an induction motor as influenced by magnetic saturation and saturated indirect vector controller have been presented. The modified model reference adaptive system has been used to estimate the stator resistance in parallel with rotor speed for accurate estimation of rotor speed. The parallel rotor speed and stator resistance estimation algorithm requires the knowledge of magnetizing inductance which varies with saturation level in the machine, so it has been modified with an online magnetizing inductance estimator. Digital simulations have been carried out in order to demonstrate the correctness of the proposed drive system. It is concluded that the consideration of magnetic saturation in the dynamic model of the machine and the control part of the system conform with a real simulation of the drive system.

\section{DYNAMIC MODEL OF INDUCTION MOTOR AS INFLUENCED BY MAGNETIC CIRCUIT SATURATION}

To accommodate the effect of magnetic-circuit saturation, the dynamic model of the induction motor in the stationary $d^{s}-q^{s}$ reference frame [13]-[15] has been modified to include the saturation of the main flux path as follows:

$$
\begin{aligned}
& \frac{d i_{d s}^{s}}{d t}=\frac{1}{L_{d s}}\left[V_{d s}^{s}-R_{s} i_{d s}^{s}-L_{2 s} \frac{d i_{q s}^{s}}{d t}-L_{d m} \frac{d i_{d r}^{s}}{d t}-L_{2 s} \frac{d i_{q r}^{s}}{d t}\right] \\
& \frac{d i_{q s}^{s}}{d t}=\frac{1}{L_{q s}}\left[V_{q s}^{s}-L_{2 s} \frac{d i_{d s}^{s}}{d t}-R_{s} i_{q s}^{s}-L_{2 s} \frac{d i_{d r}^{s}}{d t}-L_{q m} \frac{d i_{q r}^{s}}{d t}\right] \\
& \frac{d i_{d r}^{s}}{d t}=\frac{1}{L_{d r}}\left[-L_{d m} \frac{d i_{d s}^{s}}{d t}-\left(L_{2 s} \frac{d}{d t}+\omega_{r} L_{m}\right) i_{q s}^{s}-R_{r} i_{d r}^{s}-\left(L_{2 s} \frac{d}{d t}+\omega_{r} L_{d r}\right) i_{q r}^{s}\right] \\
& \frac{d i_{q r}^{s}}{d t}=\frac{1}{L_{q r}}\left[-\left(L_{2 s} \frac{d}{d t}-\omega_{r} L_{m}\right) i_{d s}^{s}-L_{q m} \frac{d i_{q s}^{s}}{d t}-\left(L_{2 s} \frac{d}{d t}-\omega_{r} L_{q r}\right) i_{d r}^{s}-R_{r} i_{q r}^{s}\right]
\end{aligned}
$$

The stator and rotor mutual inductance of the d-and q- axes in the above equations are expressed as:

$$
L_{d m}=L_{0}+L_{2 c}, \quad L_{q m}=L_{0}-L_{2 c}
$$

The stator and rotor self inductances of the d- and q-axes in equations (1)-(4) are defined by:

$$
\begin{aligned}
& L_{d s}=L_{l s}+L_{d m}, \quad L_{d r}=L_{l r}+L_{d m} \\
& L_{q s}=L_{l s}+L_{q m}, L_{q r}=L_{l r}+L_{q m}
\end{aligned}
$$

Where

$$
\begin{aligned}
& L_{2 c}=L_{2} \cos (2 \mu), L_{2 s}=L_{2} \sin (2 \mu) \\
& L_{0}=\frac{L+L_{m}}{2}, L_{2}=\frac{L-L_{m}}{2}
\end{aligned}
$$


$L=d\left|\lambda_{m}\right| / d\left|i_{m}\right|$ is a dynamic mutual inductance equal to the first derivative of the magnetization curve. $L_{m}=\left|\lambda_{m}\right| /\left|i_{m}\right|$ is a static mutual inductance and can be also obtained directly from the magnetization curve. Evidently both $L$ and $L_{m}$ take account of the fact that $i_{m}$ is continuously changing in time. And $\mu$ is the angle of the magnetizing current space vector with respect to the reference axis.

The electromagnetic torque can be expressed as:

$T_{e}=\frac{3}{2} \frac{P}{2} L_{m}\left(i_{q s}^{s} i_{d r}^{s}-i_{d s}^{s} i_{q r}^{s}\right)$

The equation of the motion is:

$J \frac{d \omega_{r}}{d t}+f_{d} \omega_{r}+T_{l}=T_{e}$

The state form of equation (6) can be written as:

$\frac{d \omega_{r}}{d t}=\frac{T_{e}-f_{d} \omega_{r}-T_{L}}{J}$

Thus the dependent variables of the system are $i_{d s}^{s}, i_{q s}^{s}, i_{d r}^{s}, i_{q r}^{s}$ and $\omega_{r}$. The derivatives of these variables are functions of the variables themselves, motor parameters and stator supply voltage. Simultaneous integration of equations (1)-(5) and (7) predicts the temporal variation of these variables.

\section{3- SATURATED INDIRECT VECTOR CONTROLLER OF THE INDUCTION MOTOR}

The estimation of rotor flux value and its phase angle is performed in rotor flux oriented $d^{e}-q^{e}$ synchronously rotating reference frame based on stator currents and speed measurement.

The rotor flux calculator is derived in such a way that nonlinear relationship between the main flux and magnetizing current is taken into account. In this calculation, the field orientation is maintained, the condition $\lambda_{q r}=0$ is satisfied, the influence of q-axis magnetizing flux on the resultant magnetizing flux can be neglected [14] $\left(\lambda_{q m}=0\right)$. The approximate saturated rotor flux calculator is given with:

$\lambda_{d m}=\frac{L_{l r}}{R_{r}} \frac{d \lambda_{r}}{d t}+\lambda_{r}$

$\omega_{s l}=\frac{L_{m}}{T_{r}} \frac{i_{q s}^{e}}{\lambda_{r}}$

$\lambda_{d m}=\lambda_{r}+L_{l r}\left[i_{d s}^{e}-i_{d m}\left(\lambda_{m}\right)\right]$

$T_{e}=\frac{3}{4} P \frac{L_{m}}{L_{r}} i_{q s}^{e} \lambda_{r}$ 
Simplified saturated indirect vector controller can be constructed as shown in Fig. 1 the scheme is described with the following equations:

$$
\begin{aligned}
& \lambda_{m} \approx \lambda_{d m}=\frac{L_{l r}}{R_{r}} \frac{d \lambda_{r}^{*}}{d t}+\lambda_{r}^{*} \\
& i_{d s}^{e^{*}}=i_{d m}\left(\lambda_{m}\right)+\frac{1}{R_{r}} \frac{d \lambda_{r}^{*}}{d t} \\
& i_{q s}^{e^{*}}=\frac{4}{3 P} \frac{\left(L_{l r}+L_{m}\right)}{L_{e}{ }^{*}} \frac{\lambda_{r}^{*}}{L_{r}} \\
& \omega_{s l}^{*}=\frac{L_{m}}{T_{r}} \frac{i_{q s}^{e^{*}}}{\lambda_{r}^{*}} \theta_{e}^{*}=\int\left(\omega_{r}+\omega_{s l}^{*}\right) d t
\end{aligned}
$$

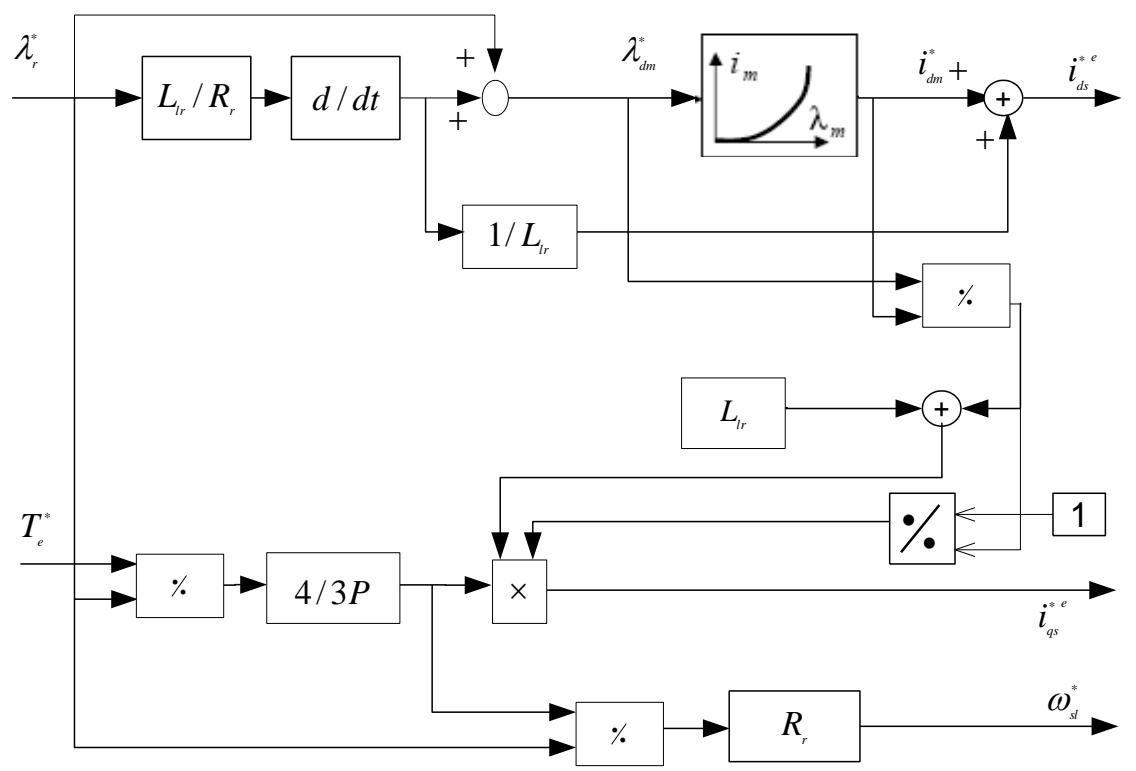

Figure 1: Saturated indirect vector controller scheme

\section{4- PARALLEL STATOR RESISTANCE AND ROTOR SPEED ESTIMATION}

Accurate knowledge of stator resistance is not required in indirect field oriented control scheme. However, the speed estimation from the machine terminal quantities depends on the machine model as MRAS technique. The disadvantages of this method are that the stator resistance $R_{s}$ detuning causes rotor speed $\omega_{r}$ and torque response deterioration in the low speed range [11]. 
The basic MRAS rotor speed estimator described in [10] and illustrated in Fig. 2. The reference model and adjustable model in this estimator blocks perform integration of (17) and (18). It relies on measured stator currents and measured stator voltages and is composed of the reference (voltage) and the adjustable (current) model. The estimator operates in the stationary reference frame and it is described with the following equations [10]:

$$
\begin{aligned}
& p \underline{\hat{\lambda}}_{r V}^{s}=\frac{L_{r}}{L_{m}}\left[\underline{V}_{s}^{s}-\left(\hat{R}_{s}+\sigma L_{s} p\right)\right] \underline{i}_{s}^{s} \\
& p \underline{\hat{\lambda}}_{r I}^{s}=\frac{L_{m}}{T_{r}} \underline{i}_{s}^{s}-\left(\frac{1}{T_{r}}-j \hat{\omega}\right) \hat{\hat{\lambda}}_{r I}^{s} \\
& \hat{\omega}=\left(K_{p \omega}+\frac{K_{I \omega}}{p}\right) e_{\omega} \\
& e_{\omega}=\underline{\hat{\lambda}}_{r I}^{s} \times \underline{\hat{\lambda}}_{r V}^{s}=\hat{\lambda}_{d r I}^{s} \hat{\lambda}_{q r V}^{s}-\hat{\lambda}_{q r I}^{s} \hat{\lambda}_{d r V}^{s}
\end{aligned}
$$

A hat above a symbol in (17)-(20) denotes estimated quantities. All of the parameters in the motor and the estimator are assumed to be of the same value, except for the stator resistance [hence, a hat above the symbol in (17)]. Underlined variables are space vectors and subscripts $V$ and $I$ stand for the outputs of the voltage (reference) and current (adjustable) models, respectively. Voltage, current, and flux are denoted with $V, I$ and $\lambda$, respectively, and subscripts $s$ and $r$ stand for stator and rotor, respectively. Superscript $s$ in space vector symbols denotes the stationary reference frame.

The accuracy of estimated speed depends on the fluxes $\underline{\lambda} \stackrel{s}{r V}$ derived from stator model of the induction motor. This flux estimation is dependent on the stator resistance $R_{s}$ of the induction motor as shown by equation (17). At low speeds, the low voltages and variations in the stator resistance due to temperature rise and switch voltage drops, dead times tend to reduce the accuracy of the estimated signals. The error in $\underline{\lambda}{ }_{r V}^{s}$ estimation due to variation in $R_{s}$ is known to introduce significant error in speed estimation for speed sensorless drive. These provide the incentive stator resistance $R_{s}$ estimation. [1].

As is evident from (17)-(20) and Fig. 2, the adaptive mechanism (PI controller) relies on an error quantity that represents the difference between the instantaneous positions of the two rotor flux estimates. The second degree of freedom and the difference in amplitudes of the two rotor flux estimates is not utilized. The parallel rotor speed and stator resistance MRAS estimation scheme will make use of this second degree of freedom to achieve simultaneous estimation of the two quantities. The role of the reference and the adjustable model will be interchanged for this purpose, since the rotor flux estimate of (18) is independent of stator resistance. 


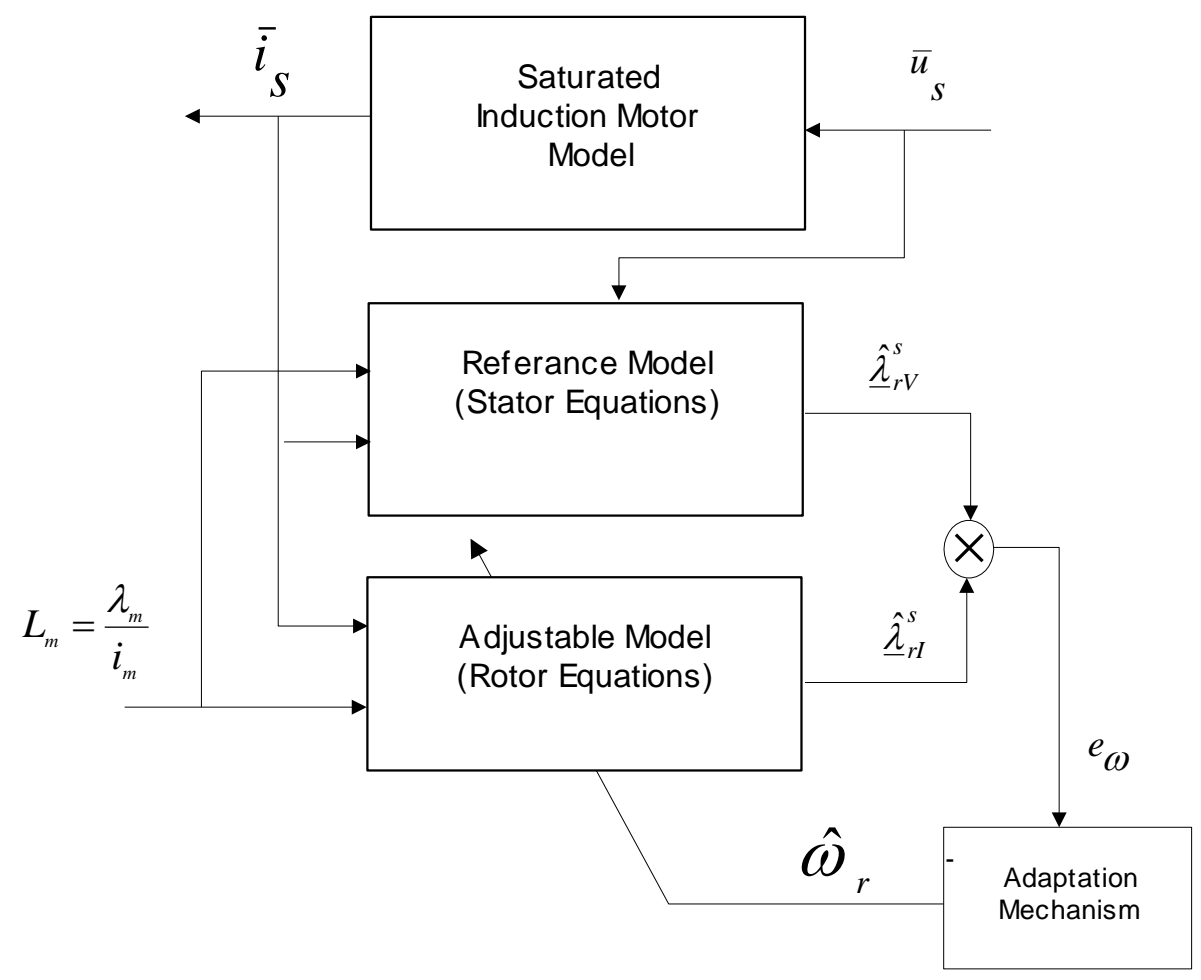

Figure 2: Basic configuration of saturated MRAS speed estimation

Parallel rotor speed and stator resistance estimation scheme is designed based on the concept of hyperstability [10] in order to make the system asymptotically stable. For the purpose of deriving an adaptation mechanism, it is valid to initially treat rotor speed as a constant parameter, since it changes slowly compared to the change in rotor flux. The stator resistance of the motor varies with temperature, but variations are slow so that it can be treated as a constant parameter, too. The configuration of the proposed parallel rotor speed and stator resistance is shown in Fig. 3.

Let $R_{S}$ and $\omega$ denote the true values of the stator resistance in the motor and rotor speed, respectively. These are in general different from the estimated values. Consequently, a mismatch between the estimated and true rotor flux space vectors appears as well. The error equations for the voltage and the current model outputs can then be written as

$$
\begin{aligned}
& p \underline{\varepsilon}_{V}=-\frac{L_{r}}{L_{m}}\left(R_{s}-\hat{R}_{s}\right) \underline{i}_{s}^{s} \\
& \underline{\varepsilon}_{V}=\underline{\lambda}_{r V}^{s}-\underline{\hat{\lambda}}_{r V}^{s}=\varepsilon_{d V}+j \varepsilon_{q V} \\
& p \underline{\varepsilon}_{I}=\left(j \omega-\frac{1}{T_{r}}\right) \underline{\varepsilon}_{I}+j(\omega-\hat{\omega}) \underline{\hat{\lambda}}_{r I}^{s} \\
& \underline{\varepsilon}_{I}=\underline{\lambda}_{r I}^{s}-\underline{\hat{\lambda}}_{r I}^{s}=\varepsilon_{d I}+j \varepsilon_{q I}
\end{aligned}
$$




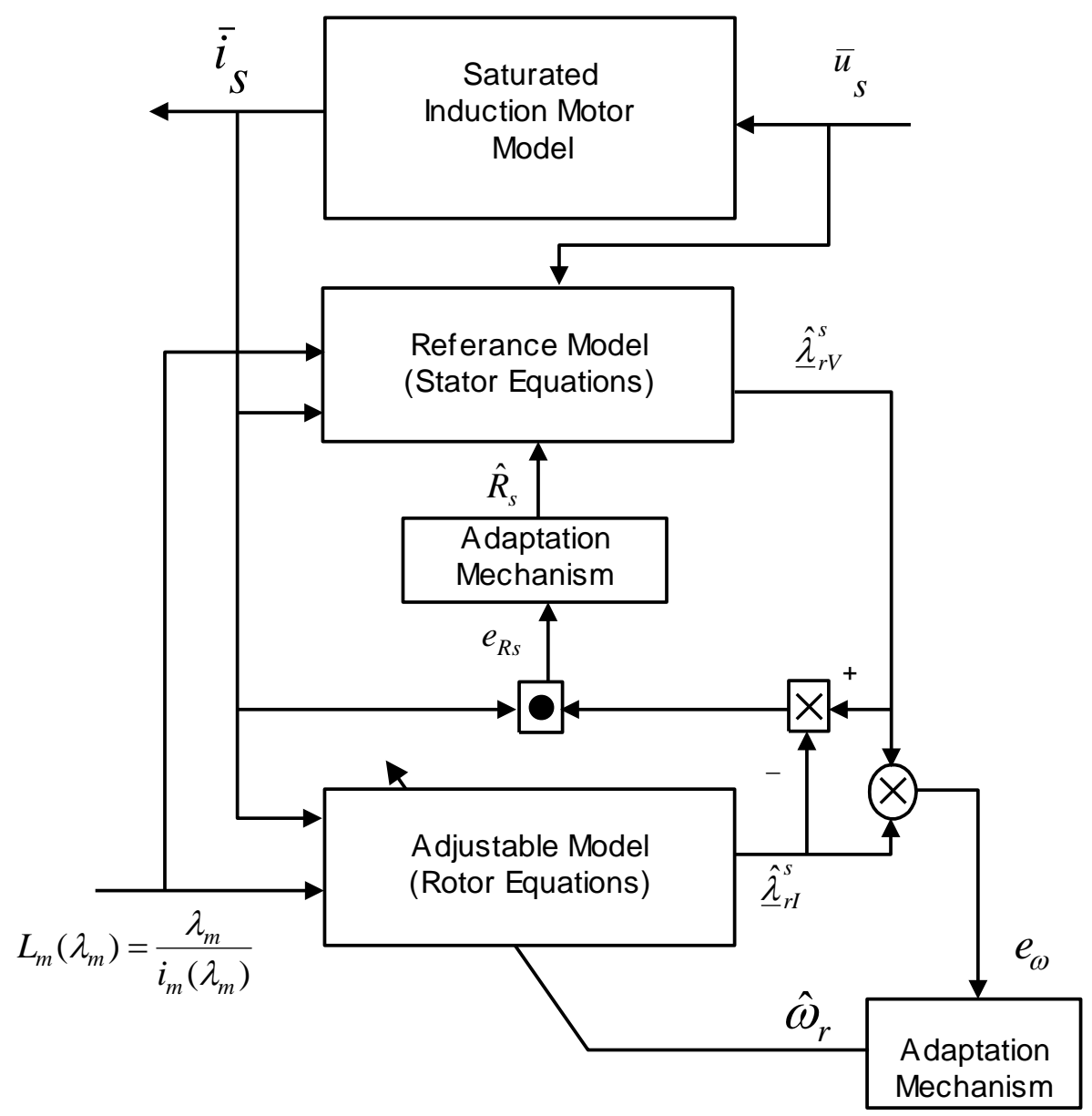

Figure 3: Structure of saturated MRAS system for parallel rotor speed and stator resistance estimation

Symbols $\underline{\lambda}_{r V}^{s}, \underline{\lambda}_{r I}^{s}$ in the above equations stand for true values of the two rotor flux space vectors. Equations (21), (22) can be rewritten in matrix notation as

$$
p\left[\begin{array}{c}
\varepsilon_{d I} \\
\varepsilon_{q I} \\
\varepsilon_{d V} \\
\varepsilon_{q V}
\end{array}\right]=\left[\begin{array}{cccc}
-\frac{1}{T_{r}} & -\omega & 0 & 0 \\
\omega & -\frac{1}{T_{r}} & 0 & 0 \\
0 & 0 & 0 & 0 \\
0 & 0 & 0 & 0
\end{array}\right] \cdot\left[\begin{array}{c}
\varepsilon_{d I} \\
\varepsilon_{q I} \\
\varepsilon_{d V} \\
\varepsilon_{q V}
\end{array}\right]-W=A \underline{\varepsilon}-W
$$

where $\underline{\varepsilon}^{T}=\left[\begin{array}{llll}\varepsilon_{d I} & \varepsilon_{q I} & \varepsilon_{d V} & \varepsilon_{q V}\end{array}\right]=\left[\begin{array}{ll}\underline{\varepsilon}_{I}^{T} & \underline{\varepsilon}_{V}^{T}\end{array}\right]$ and $W$ is the nonlinear block, defined as follows: 


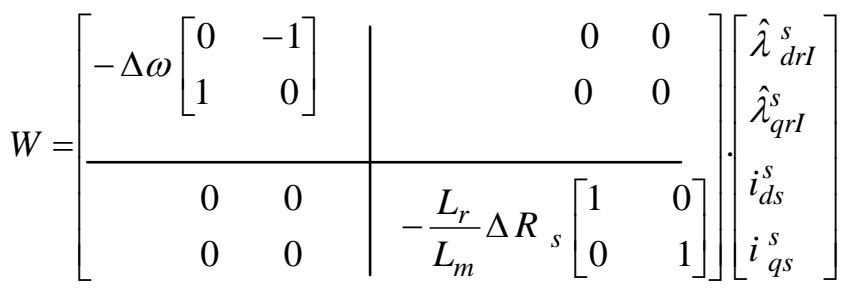

$$
\begin{aligned}
& W=\left[\begin{array}{c|c}
-\Delta \omega \mathrm{J} & 0 \\
\hline 0 & -\frac{L_{r}}{L_{m}} \Delta R_{s} \mathrm{I}
\end{array}\right] \cdot\left[\begin{array}{l}
\underline{\hat{\lambda}}_{r I}^{s} \\
\underline{\mathrm{i}}^{s} s
\end{array}\right]
\end{aligned}
$$

where

$$
\begin{aligned}
& \Delta \omega=\omega-\hat{\omega}, \Delta R_{s}=R_{s}-\hat{R}_{s}, \underline{\hat{\lambda}}_{r I}^{s}=\left[\begin{array}{ll}
\hat{\lambda}_{d r I}^{s} & \hat{\lambda}_{q r I}^{s}
\end{array}\right]^{T}, \underline{i}_{s}^{s}=\left[\begin{array}{ll}
i_{d s}^{s} & i_{q s}^{s}
\end{array}\right]^{T}, \\
& \mathrm{~J}=\left[\begin{array}{rr}
0 & -1 \\
1 & 0
\end{array}\right], \mathrm{I}=\left[\begin{array}{rr}
1 & 0 \\
0 & 1
\end{array}\right]
\end{aligned}
$$

The system is hyperstable if the input and output of the nonlinear block $W$ satisfies Popov's criterion [10]:

$$
\begin{aligned}
\mathrm{s} & =\int_{0}^{t_{1}} \underline{\varepsilon}^{T} \cdot W d t \\
& =-\int_{0}^{t_{1}} \Delta \omega\left(\underline{\varepsilon}_{I}^{T} \cdot \mathrm{J} \cdot \underline{\hat{\lambda}}_{r I}^{s}\right) d t+\frac{L_{r}}{L_{m}} \int_{0}^{t_{1}} \Delta R_{s}\left(\underline{\varepsilon}_{V}^{T} \cdot \underline{i}_{-s}^{s}\right) d t \\
& =S_{1}+\frac{L_{r}}{L_{m}} S_{2} \geq-\gamma^{2} \\
\underline{\varepsilon}^{T} . W & =-\Delta \omega\left(\underline{\varepsilon}_{I}^{T} . \mathrm{J} \cdot \underline{\hat{\lambda}}_{r I}^{s}\right)+\frac{L_{r}}{L_{m}} \Delta R_{S}\left(\underline{\varepsilon}_{V}^{T} \cdot \underline{i}_{s}^{s}\right)
\end{aligned}
$$

The validity of eq. (25) can be verified using inequality eqs. (27), (28) with adaptive mechanisms eqs. (29), (30) for rotor speed estimation and stator resistance identification, respectively:

$$
\begin{aligned}
S_{1} & =-\int_{0}^{t_{1}} \Delta \omega\left(\underline{\varepsilon}_{I}^{T} \cdot \mathrm{J} \cdot \underline{\hat{\lambda}}_{r I}^{s}\right) d t \geq-\gamma_{1}^{2} \\
S_{2} & =\frac{L_{r}}{L_{m}} \int_{0}^{t_{1}} \Delta R_{s}\left(\underline{\varepsilon}_{V}^{T} \cdot \underline{i}_{s}^{s}\right) d t \geq \gamma_{2}^{2} \\
\hat{\omega} & =\left(K_{p \omega}+\frac{K_{I \omega}}{p}\right)\left(\underline{\varepsilon}_{I}^{T} \cdot \mathbf{J} \cdot \underline{\hat{\lambda}}_{r I}^{s}\right) \\
& =\left(K_{p \omega}+\frac{K_{I \omega}}{p}\right)\left(\underline{\hat{\lambda}}_{r I}^{s} \times \underline{\hat{\lambda}}_{r V}^{s}\right)
\end{aligned}
$$




$$
\hat{\omega}=\left(K_{p \omega}+\frac{K_{I \omega}}{p}\right) e_{\omega}
$$

where $e_{\omega}=\hat{\lambda}{ }_{d r I}^{s} \hat{\lambda}{ }_{q r V}^{s}-\hat{\lambda}{ }_{q r I}^{s} \hat{\lambda}{ }_{d r V}^{s}$

$$
\begin{aligned}
\hat{R}_{s} & =\left(K_{p R_{S}}+\frac{K_{I R_{s}}}{p}\right)\left(-\underline{\varepsilon}_{V}^{T} \cdot \underline{i}_{s}^{s}\right) \\
& =\left(K_{p R_{S}}+\frac{K_{I R_{s}}}{p}\right)\left[\underline{i}_{s}^{s} \cdot\left(\underline{\hat{\lambda}}_{r V}^{s}-\underline{\hat{\lambda}}_{r I}^{s}\right)\right] \\
\hat{R}_{s} & =\left(K_{p R_{S}}+\frac{K_{I R_{s}}}{p}\right) e_{R s}
\end{aligned}
$$

where $e_{R s}=\hat{i}_{d s}^{s}\left(\hat{\lambda}_{d r V}^{s}-\hat{\lambda}_{d r I}^{s}\right)+i_{q s}^{s}\left(\hat{\lambda}_{q r V}^{s}-\hat{\lambda}_{q r I}^{s}\right)$

where $K_{p \omega}, K_{I \omega}, K_{p R_{S}}$ and $K_{I R_{s}}$ are PI parameters of $\omega$ and $R_{s}$ adaptation mechanisms. The values of $\omega$ and $R_{s}$ can be estimated by eq. (29) and eq. (30) parallel at any $\omega$. The adaptation mechanism eq. (29) is the same as in customary MRAS speed estimator, having only the speed estimation mechanism eq. (20).

\section{5- ONLINE IDENTIFICATION ALGORITHM OF MAGNETIZING INDUCTANCE}

The accuracy of speed estimation depends on the precise magnetizing inductance which varies due to the main flux saturation. Magnetizing inductance of an induction motor may vary significantly when the main magnetic flux is saturated. Standard assumption of constant magnetizing inductance is no longer valid and it becomes necessary to compensate for the nonlinear magnetizing inductance variation. Therefore, the structure of the speed estimator should be modified in such a way that the variation of main flux saturation is recognized within the speed estimation algorithm. This requires online identification algorithm of the magnetizing inductance [8-9].

The magnitude of magnetic flux vector is calculated from its components as:

$\lambda_{m}=\sqrt{\lambda{ }_{d m}^{s^{2}+\lambda{ }_{q m}^{2}}}$

The air-gap magnetizing flux components can be obtained in the stationary reference frame [9] as:

$\lambda_{d m}^{s}=\int\left(V_{d s}^{s}-R_{s} i_{d s}^{s}\right) d t-L_{l s} i_{d s}^{s}$

$\lambda_{q m}^{s}=\int\left(V_{q s}^{s}-R_{s} i_{q s}^{s}\right) d t-L_{l s} i_{q s}^{s}$

The magnetizing curve of the machine is identified offline in the laboratory from noload test and is represented with a suitable polynomial relating the magnetizing flux with the magnetizing current. Since the magnetizing flux is known, it is possible to estimate the magnetizing inductance using the known non linear inverse magnetizing curve. 


$$
\begin{aligned}
& i_{m}=f\left(\lambda_{m}\right) \\
& \hat{L}_{m}=\frac{\lambda_{m}}{i_{m}\left(\lambda_{m}\right)}
\end{aligned}
$$

\section{6- PROPOSED SENSORLESS VECTOR CONTROLLED INDUCTION MOTOR DRIVE}

Figure 4 shows the block diagram of the proposed sensorless indirect vector controlled induction motor drive taking saturation into account. It consists mainly of a loaded induction motor model taking saturation into account, a hysteresis current-controlled PWM (CCPWM) inverter, a saturated vector control scheme followed by a coordinate transformation (CT) and an outer speed loop. In addition to the machine and inverter the system include speed controller together with a parallel stator resistance and motor speed estimator based on MRAS. To compensate the effect of nonlinear magnetizing inductance due to saturation in the accuracy of rotor speed estimation, an online magnetizing inductance estimator has been constructed and used within rotor speed estimator. The magnetizing inductance is estimated based on the measured stator voltages and currents and the inverse magnetizing curve of the machine. The speed controller generates the command $q^{e}$-components of stator current $i_{q s}^{*^{e}}$ from the speed error between the estimated motor speed and the command speed. The rotor flux reference decreases in inverse proportion to the speed of rotation in the field weakening region, while it is constant and equal to rated rotor flux $\lambda_{m}$ in the base speed region as also shown in Fig. 4 and is used to fed the saturated vector controller scheme for obtaining the command of stator current $i_{d s}^{*}$.

Measurements of two stator phase voltages and currents are transformed to $d^{s}$ - and $q^{s}$ - components and are used in the parallel stator resistance, speed and online magnetizing estimators. The coordinate transformation (CT) in Fig. 4 is used to transform the stator currents components command $\left(i_{q s}^{*}{ }^{e}\right.$ and $\left.i_{d s}^{*}\right)$ to the three phase stator current command $\left(i_{a s}^{*}, i_{b s}^{*}\right.$ and $\left.i_{c s}^{*}\right)$ by using the field angle $\theta_{e}^{*}$. The hysteresis current control compares the stator current to the actual currents of the machine and switches the inverter transistors in such a way that the commanded currents are obtained.

\section{7- SIMULATION RESULTS AND DISCUSSIONS}

Computer simulations have been carried out in order to validate the effectiveness of the proposed scheme of Fig. 4. The Matlab / Simulink software package has been used for this purpose. 


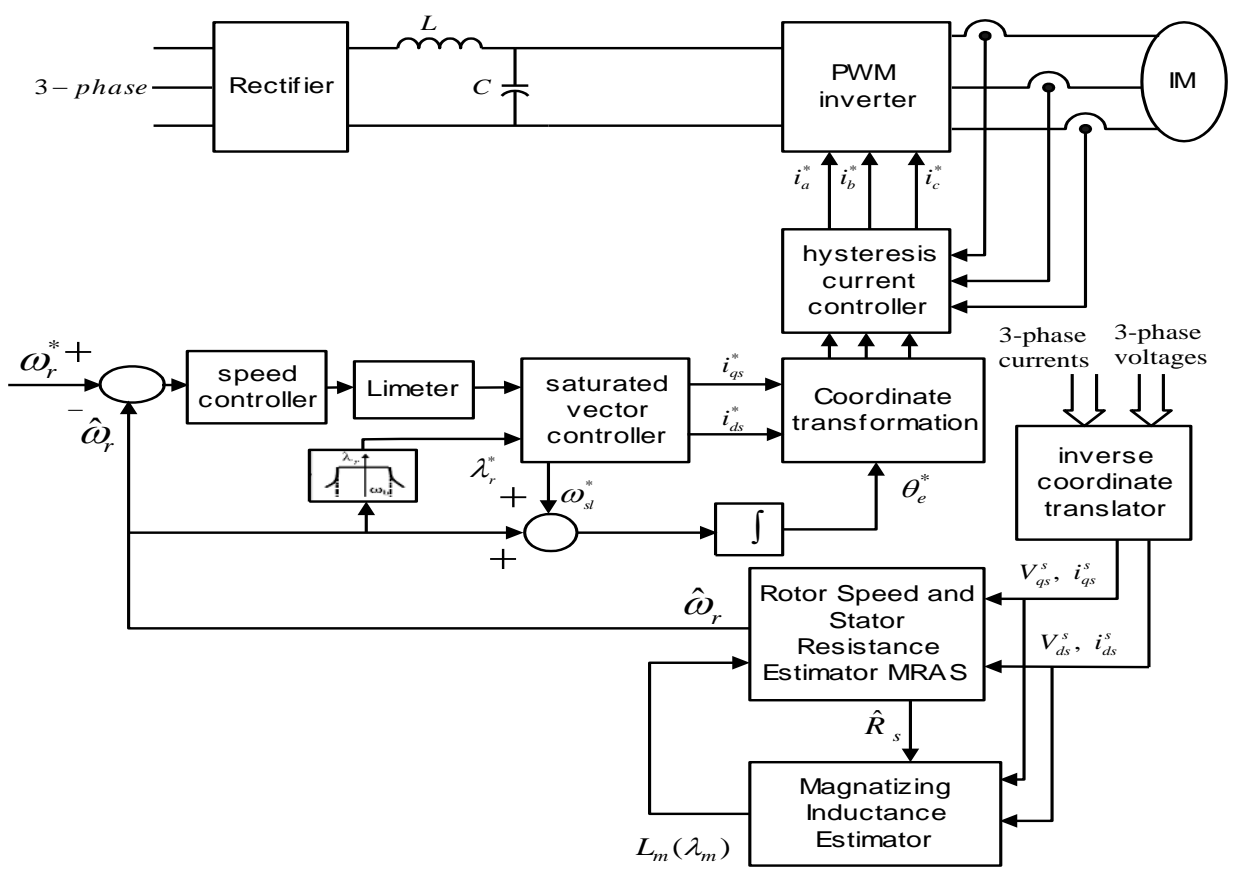

Figure 4: Overall block diagram of the proposed sensorless vector controlled induction motor drive

The induction motor under study is a $3.8 \mathrm{HP}$, four poles motor, whose nominal parameters and specifications are listed in table 1 . The actual value of the magnetizing inductance in the motor model is considered to account for the magnetic circuit saturation as measured in the laboratory. It is represented as a function of the magnetizing current $I_{m}$ by a suitable polynomial in the Appendix I.

Table 1: Parameters and data specifications of the induction motor

\begin{tabular}{|c|c|c|c|}
\hline Rated power $(\mathrm{HP})$ & 3.8 & Rated voltage $(\mathrm{V})$ & 380 \\
\hline Rated current $(\mathrm{A})$ & 8 & Rated frequency $(\mathrm{Hz})$ & 50 \\
\hline $\operatorname{Rs}(\Omega)$ & 1.725 & $\operatorname{Rr}(\Omega)$ & 1.009 \\
\hline $\mathrm{Ls}(\mathrm{H})$ & 0.1473 & $\operatorname{Lr}(\mathrm{H})$ & 0.1473 \\
\hline $\mathrm{Lm}(\mathrm{H})$ & 0.1271 & Rated rotor flux,$(\mathrm{wb})$ & 0.735 \\
\hline $\mathrm{J}\left(\mathrm{kg} \cdot \mathrm{m}^{2}\right)$ & 0.0400 & Rated speed $(\mathrm{rpm})$ & 1450 \\
\hline
\end{tabular}

The transient performance of the conventional sensorless drive system is investigated for step change of the stator resistance when the motor is running at 100 rpm with nominal load torque. Figures 5a, 5b, 5c, 5d, 5e and 5f show the vector control response when the stator resistance is increased by $33 \%$ from its nominal value at $\mathrm{t}=$ $2.5 \mathrm{sec}$. From figures $5 \mathrm{a}, 5 \mathrm{c}$ and $5 \mathrm{~d}$, it is seen that, the estimated motor speed, motor 
torque, $d^{e}-q^{e}$ axes rotor flux components are oscillating and deviate from their command values during the stator resistance variation. These deviations and oscillations may cause the vector control drive system to become unstable.
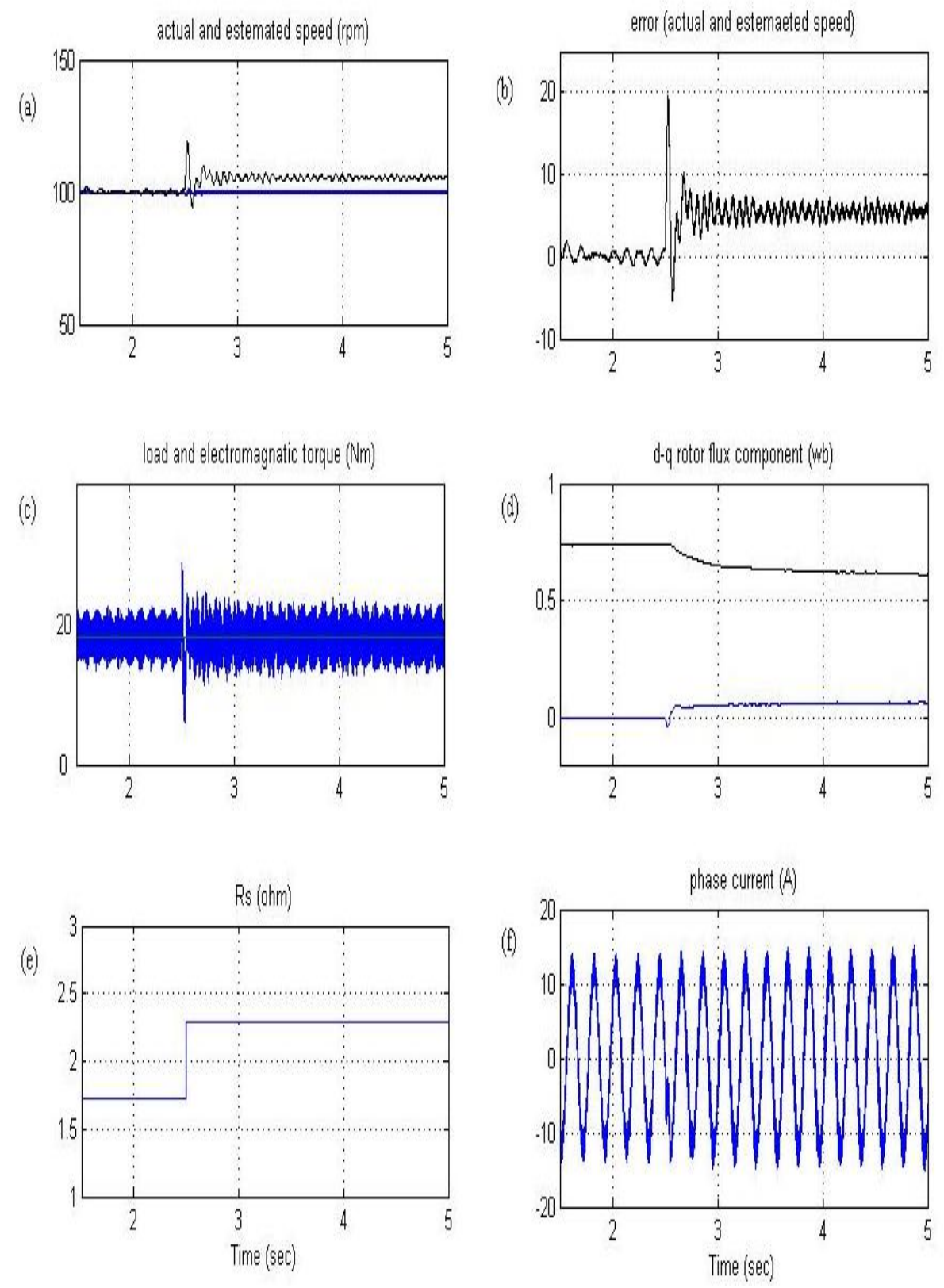

Figure 5: Effect of stator resistance variation on the motor drive performance.

(a) actual and estimated speeds, (b) error between actual and estimated speeds, (c) electromagnetic torque, (d) $d^{e}-q^{e}$ axes rotor flux components, (e) step variation of stator resistance, and (f) stator phase current. 
In order to improve the drive performance, the stator resistance estimation in parallel with the rotor speed scheme is introduced with the control system. The estimated stator resistance is able to track the change in stator resistance adequately as shown in Fig. 6e. Also, the estimated stator resistance converges and tracks its actual after a short delay time. With stator resistance estimator, the estimated speed, motor torque and $d^{e}-q^{e}$ axes rotor flux components are kept constant and matched with their commands as shown in figures $6 \mathrm{~b}, 6 \mathrm{c}$ and $6 \mathrm{~d}$.
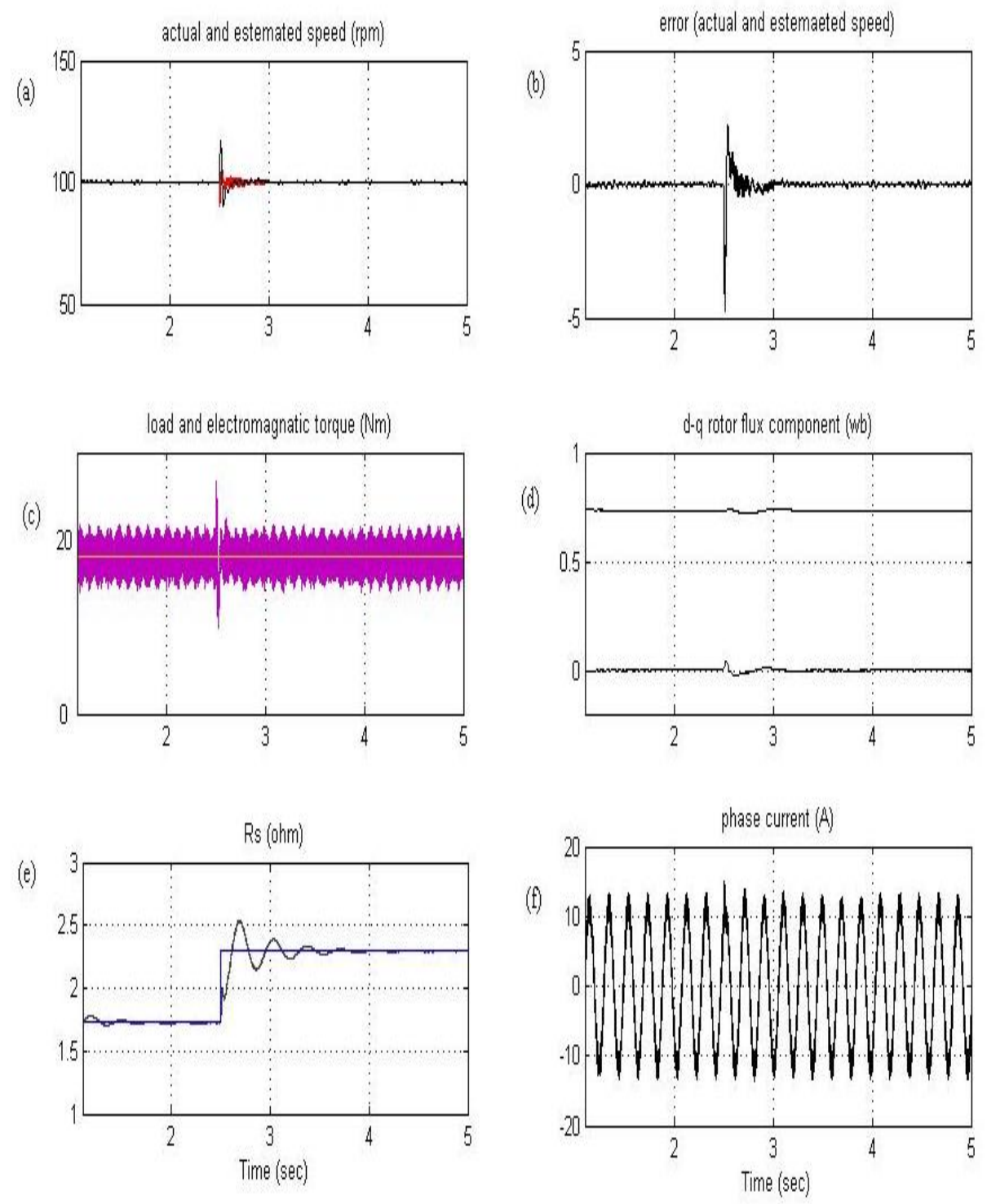

Figure 6: Motor drive performance with the parallel stator resistance and motor speed estimation. (a) actual and estimated speeds, (b) error between actual and estimated speeds, (c) electromagnetic torque, (d) $d^{e}-q^{e}$ axes rotor flux components, (e) actual and estimated stator resistance, and (f) stator phase current. 
To validate the proposed drive, its performance has been tested at very low speed as $10 \mathrm{rpm}$. Figures $7 \mathrm{a}, 7 \mathrm{~b}, 7 \mathrm{c}, 7 \mathrm{~d}, 7 \mathrm{e}$ and $7 \mathrm{f}$ show the vector control response when the stator resistance is increased by a $33 \%$ from its nominal value in ramp change. Figures $7 \mathrm{~b}, 7 \mathrm{c}$ and $7 \mathrm{f}$ show the estimated and actual speed, the electromagnetic torque and $\mathrm{d}-\mathrm{q}$ rotor flux component are kept constant and matched with their commands. Figure $7 \mathrm{~d}$ shows the error between the actual and estimated speed equal to zero.

(a)

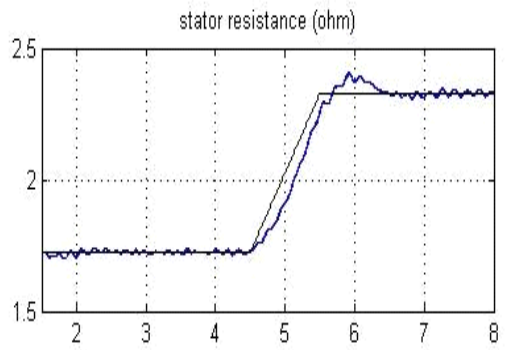

(c)

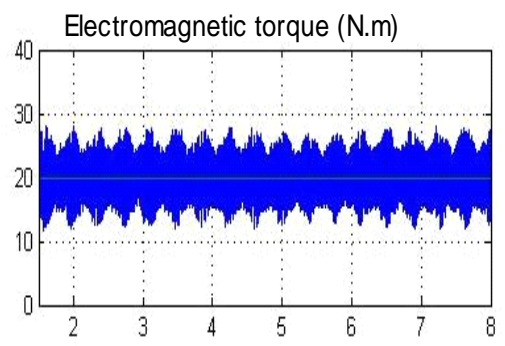

Phase stator current $(\mathrm{A})$

(e)

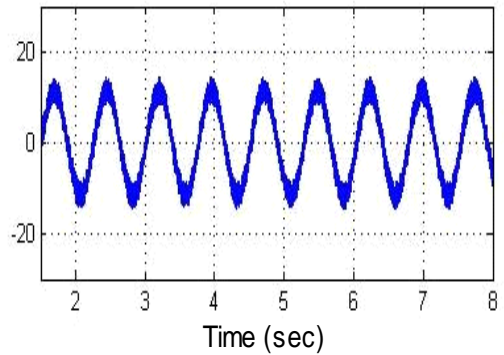

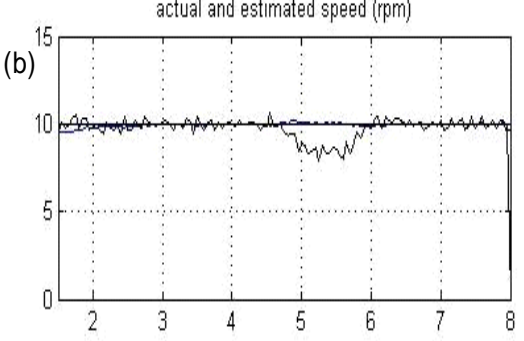

(d)
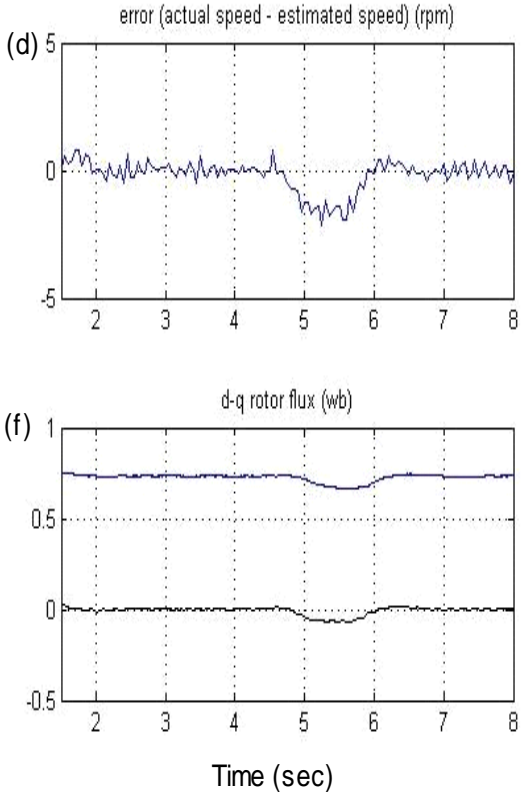

Figure 7: Motor drive performance with the parallel stator resistance and motor speed estimation. (10 rpm) (a) actual and estimated stator resistance, (b) actual and estimated speeds, (c) electromagnetic torque, (d) error between actual and estimated speeds, (f) stator phase current, and (f) $d^{e}-q^{e}$ axes rotor flux components.

The transient performance of the proposed sensorless drive system is investigated for step-change of the load torque when the actual stator resistance equals its nominal value. Figures $8 \mathrm{a}, 8 \mathrm{~b}, 8 \mathrm{c}$ and $8 \mathrm{~d}$ show the motor speed, electromagnetic torque, stator phase current and $d^{e}-q^{e}$ axes rotor flux components, when the motor subjects to a load disturbance from 10 to 20 N.m (about rated torque) at $10 \mathrm{rpm}$. Figure 8a shows the dip and overshoot of the estimated motor speed following the application 
and removal of the load torque disturbance. The speed dip and overshoot are determined by the gains of the speed controller of motor speed loop, as indicated in Fig. 8a. Figure $8 \mathrm{~b}$ shows fast and good response of the motor torque. However, this torque exhibits high-frequency pulsations of large magnitude due to voltage source inverter pulse width modulation. Figure $8 \mathrm{c}$ shows that the phase stator current is sinusoidal. The rotor flux components are unchanged during the load disturbance as shown in Fig. 8d. This proves that the decoupled control of the torque producing current from the magnetizing current is evident at low speed.

(a)

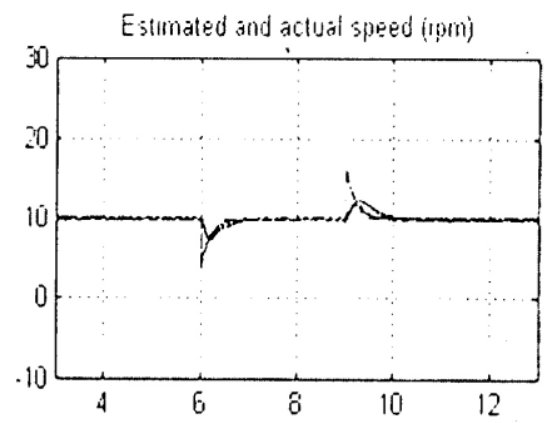

(c)

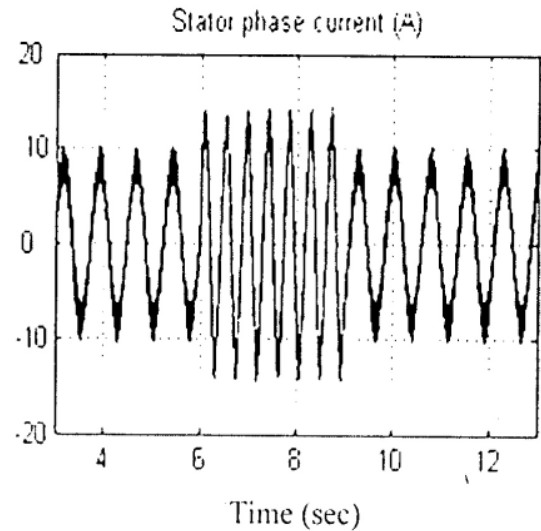

(b)

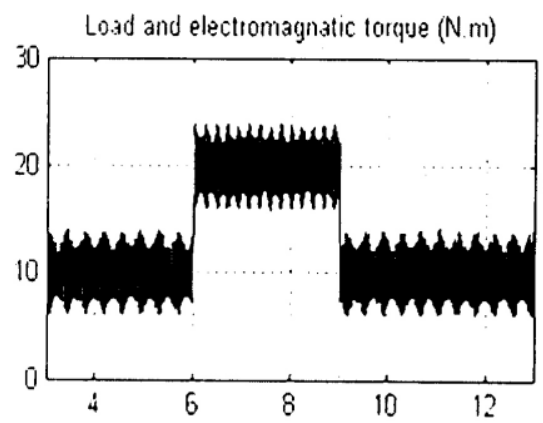

(d)

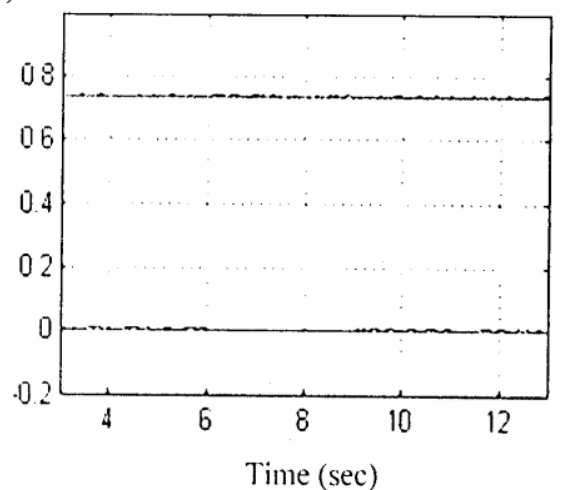

Figure 8: Performance of the proposed sensorless drive system for load torque disturbance. (a) actual and estimated rotor speed, (b) electromagnetic torque, (c) stator phase current and (d) $d^{e}-q^{e}$ axes rotor flux components.

Figure 9 shows the performance of the conventional MRAS speed estimator for speed sensorless induction motor drives when operating in the field weakening region. Figures 9a, 9b, 9c and 9d show the actual and estimated motor speed, electromagnetic torque, error between actual and estimated speeds and $d^{e}-q^{e}$ axes rotor flux components, when the motor speed command changed from $1500 \mathrm{rpm}$ to $1800 \mathrm{rpm}$ in step change fashion at $\mathrm{t}=3$ second with nominal stator resistance. The rotor flux reference decreases in inverse proportion to the speed of rotation in the field weakening region, while it is constant and equal to rated rotor flux in the base speed region. From the figure it is seen that due to operation in the field weakening region 
with reduced rotor flux command and using the nominal value of magnetizing inductance in MRAS estimator, an error between the estimated speed and actual rotor speed has been found as shown in Fig 9a. Also figure 9d shows that there exist steadystate errors between the rotor flux vector and its reference value. These performances can be improved by introducing the proposed control system scheme with using online magnetizing inductance estimation that gives an accurate value of magnetizing inductance at every level of magnetizing flux.
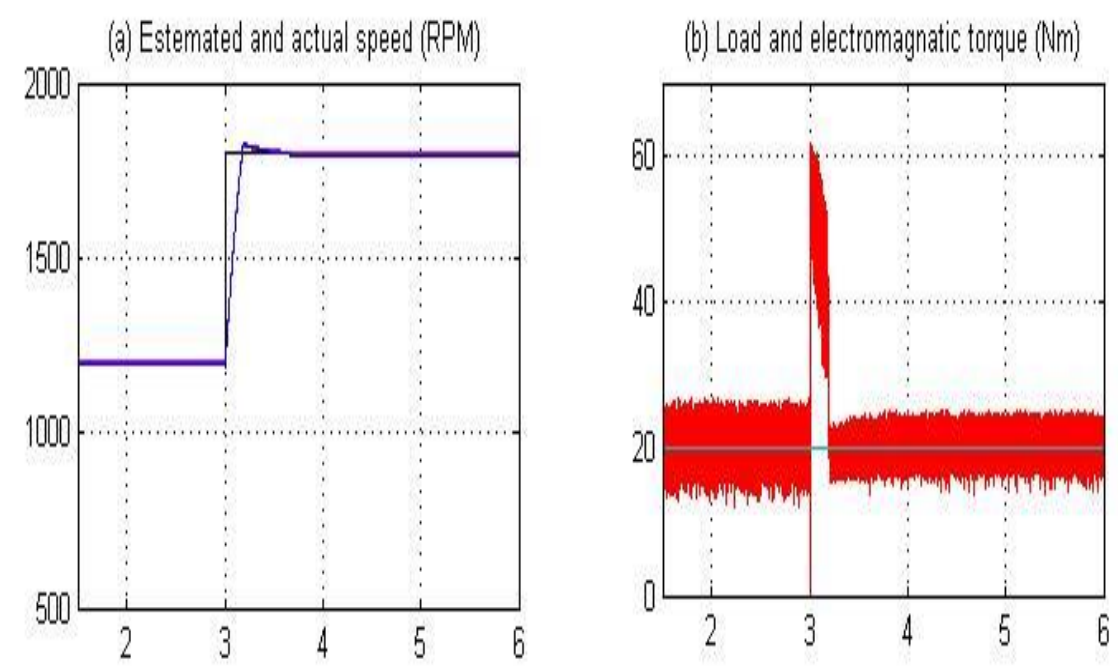

(c) Error (actual speed-estemated speed)(RPM)
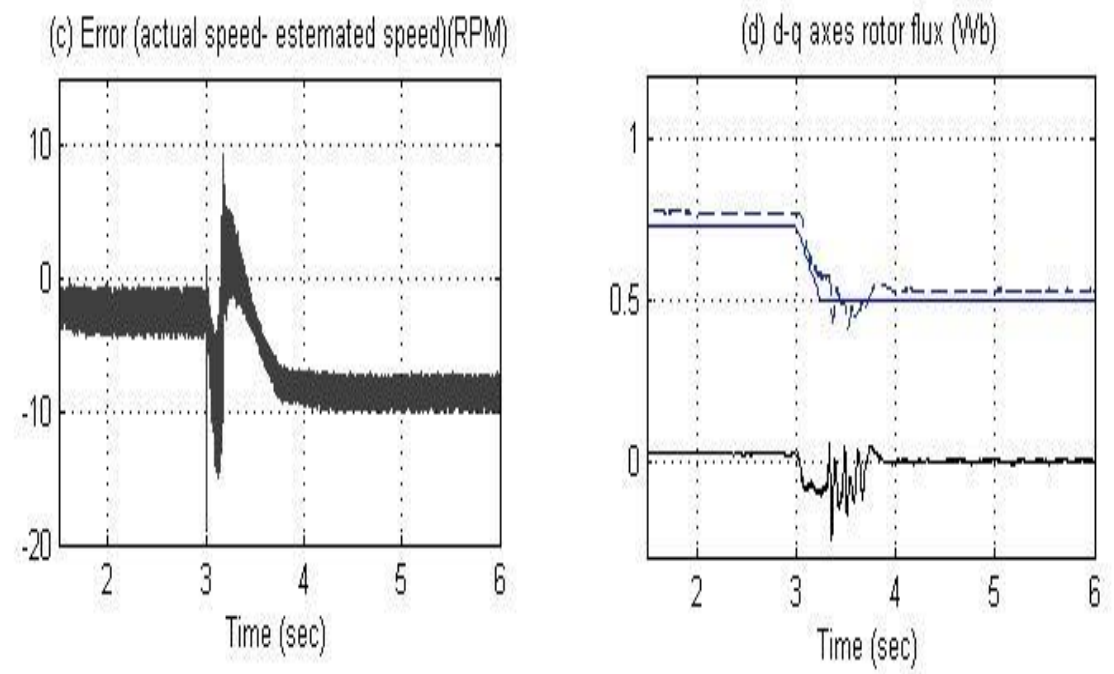

Figure 9: Performance of the conventional sensorless drive system for operation in the field weakening region.(a) actual and estimated and motor speed, (b) electromagnetic torque, (c) error between actual and estimated speeds and (d) $d^{e}-q^{e}$ axes rotor flux components. 
Figure 10 shows the performance of the control system with the proposed MRAS speed estimator. From this figure, the actual and estimated speeds have the same track as shown in Fig 10a. The rotor flux components are taken the same track as commanded value during the field weakening region as shown in Fig. 10d. This proves that the decoupled control of the torque producing current from the magnetizing current is evident at speed higher than rated speed with reduced rotor flux command.

(a) Estemated and actual speed (RPM)

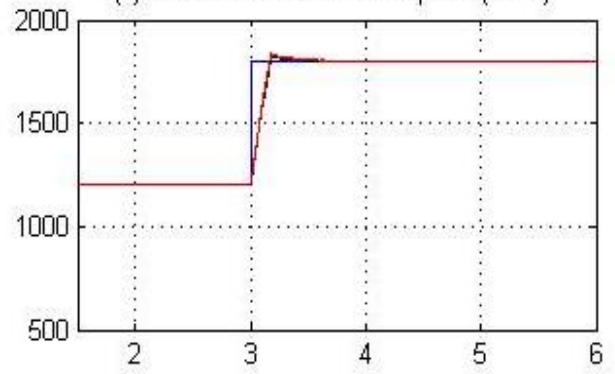

(c) Error (actual speed- estemated speed)(RPM)

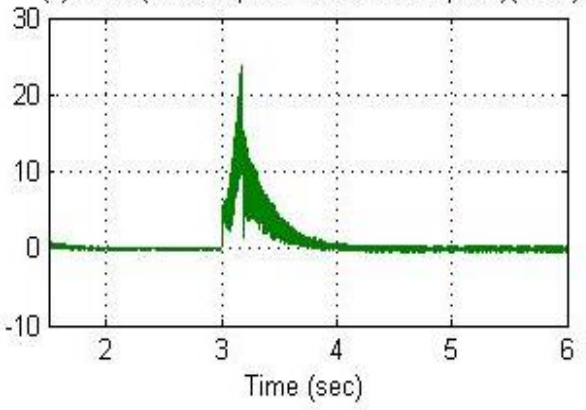

(b) Load and electromagnatic torque ( $\mathrm{Nm}$ )

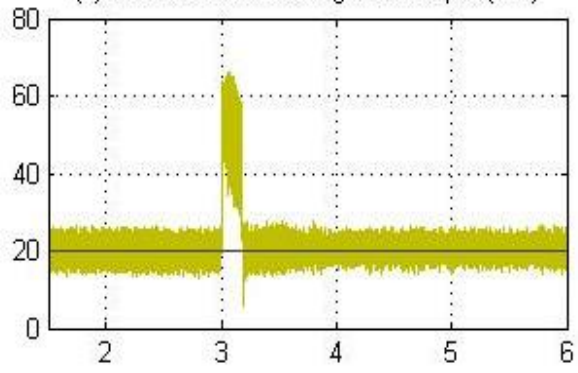

(d) d-q axes rotor flux (Wb)

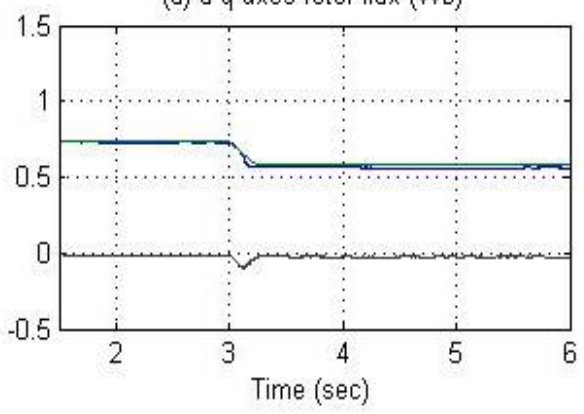

Figure 10: Performance of the proposed sensorless drive system for operation in the field weakening region.(a) actual and estimated and motor speed, (b) electromagnetic torque, (c) error between actual and estimated speeds and (d) $d^{e}-q^{e}$ axes rotor flux components

\section{8- CONCLUSIONS}

This paper investigates the stator resistance estimation for speed sensorless vector controlled induction motor drive system based on the model reference adaptive system technique taking magnetic saturation into account. An effective on-line estimation method for magnetizing inductance has been proposed to improve the drive performance. The superiority of the modified MRAS over the constant parameter one for operation with saturated main flux or stator resistance variation due to temperature variation has been proved. Simulations results are provided to demonstrate smooth steady state operation and high dynamic performance of the proposed drive system in a wide range of motor speed. 
The main conclusions that can be inferred from the results are summarized as follows:

1. The variation of stator resistance degrades the performance of the sensorless drive by introducing errors, in the estimated motor speed, motor torque and $d^{e}-q^{e}$ axes rotor flux components.

2. The parallel speed and stator resistance estimator scheme is capable of tracking the stator resistance variation very well. Then, the proposed drive scheme can be operated in very low speed range.

3. The transient performance of the proposed sensorless drive is presented when the motor is subjected to a load torque disturbance. The estimated speed response gives a desired dynamic performance which is not affected by the load torque disturbance and the variation of motor parameters. Fast and good response of the motor torque disturbance is achieved following the application and removal of load torque disturbance, this in addition to rotor flux components which are kept constant during the load disturbance.

4. Good and stable operation during field weakening under full load torque is obtained by the proposed sensorless drive system.

5. The estimation of the motor speed and stator resistance simultaneously results in accurate speed estimation and good performances are obtained in wide speed range from very low speed to speeds higher than the rated speeds. Consideration of magnetic saturation in the dynamic model of the machine and controller with stator resistance estimation scheme serve to make the motor control accurate. Therefore, the proposed sensorless drive is robust against the motor parameter variations.

\section{Appendix I}

The non-linear relationship between the air-gap voltage and the magnetizing current was measured from no-load test of the induction motor neglecting core losses. Then, the relationship between the magnetic flux and the magnetizing current (i.e. magnetizing curve) has been obtained. The data of the magnetizing curve was fitted by a suitable polynomial which is expressed as:

$\lambda_{\mathrm{m}}=0.000011 I_{\mathrm{m}}^{6}-0.00041 I_{\mathrm{m}}^{5}+0.0058_{\mathrm{m}}^{4}-0.037 I_{\mathrm{m}}^{3}+0.082 I_{\mathrm{m}}^{2}+0.15 I_{\mathrm{m}}+0.002 \mathrm{C}_{\mathrm{T}}$ he static magnetizing inductance $L_{m}$ is calculated from the above polynomial as $L_{m}=\lambda_{m}\left(I_{m}\right) / I_{m}$ and the dynamic magnetizing inductance $L$ is calculated from the first derivative of this polynomial as $L=d \lambda_{m}\left(I_{m}\right) / d I_{m}$. Figure Appendix I shows the relationship between the magnetizing flux and the magnetizing current. 


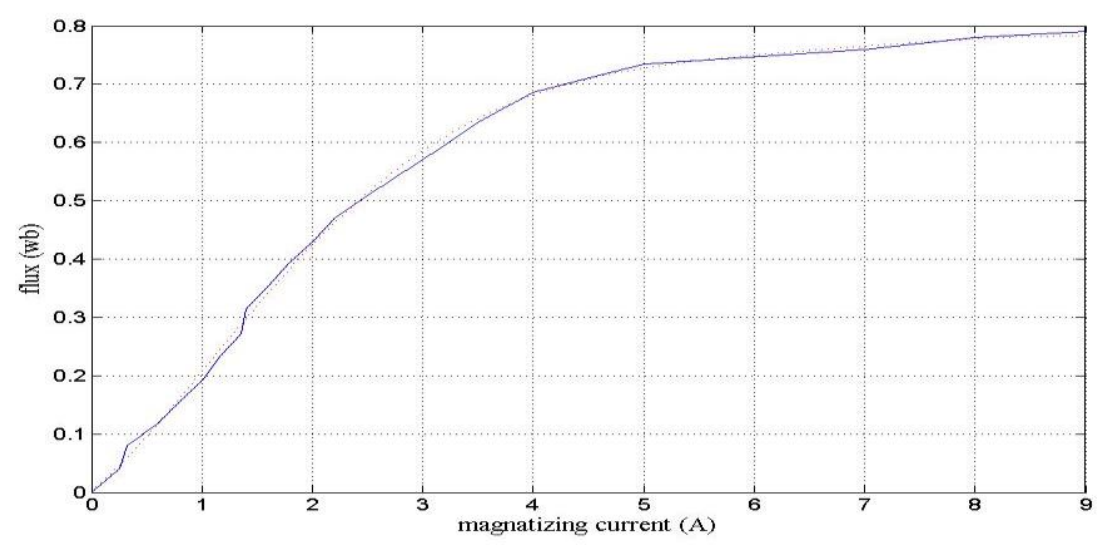

Figure App. I: Magnetizing curve of the induction machine used in simulation.

\section{REFERENCES}

[1] Veran Vasic, Slobodan N. Vukosavic, and Emil Levi, "A stator resistance estimation scheme for speed sensorless rotor flux oriented induction motor drives," IEEE Trans. on Energy Conversion, Vol. 18, No. 4, December 2003, pp. 476-483.

[2] M. S. Zaky, M. M. Khater, H. Yasin, and S. S. Shokralla, "Speed and Stator Resistance Identification Schemes for a Low Speed Sensorless Induction Motor Drive ", IEEE Conf. MEPCON, Aswan, Egypt, 2008, PP. 103-108.

[3] Gregor Edelbaher, Karel Jezernik, and Evgen Urlep, "Low-speed sensorless control of induction machine," IEEE Trans. on Ind. Electr., Vol. 53, No. 1, February 2006, PP. 120-129.

[4] Hossein Madadi Kojabadia, and Liuchen Changb, "Comparative study of pole placement methods in adaptive flux observers," Control Engineering Practice, Elsevier, Vol. 13, 2005, pp. 749-757.

[5] M. S. Zaky, M. M. Khater, H. Yasin, and S. S. Shokralla, A. El-Sabbe, "Speedsensorless control of induction motor drives (Review Paper)", Engineering Research Journal (ERJ), Faculty of Engineering, Minoufiya University, Egypt, Vol. 30, No. 4, October 2007, PP. 433-444.

[6] Hirokazu Tajima, Giuseppe Guidi, and Hidetoshi Umida, "Consideration about problems and solutions of speed estimation method and parameter tuning for speed-sensorless vector control of induction motor drives," IEEE Trans. on Ind. Applicat., Vol. 38, No. 5, September/October 2002, pp. 1282-1289.

[7] Joachim Holtz, and Juntao Quan, "Sensorless vector control of induction motors at very low speed using a nonlinear inverter model and parameter identification," IEEE Trans. on Ind. Applicat., Vol. 38, NO. 4, July/August 2002, pp. 1087-1095.

[8] Emil Levi, Matija Sokola, and Slobodan N. Vukosavic, "A method for magnetizing curve identification in rotor flux oriented induction machines," IEEE Trans. On Energy Conversion, Vol. 15, No. 2, June 2000, pp. 157-162.

[9] Emil Levi, and Mingyu Wang, "Online Identification of the Mutual Inductance for Vector Controlled Induction Motor Drives," IEEE Trans. on Energy Conversion, Vol. 18, No. 2, June 2003, pp. 299-305 
[10] C. Schauder, "Adaptive speed identification for vector control of induction motors. without rotational transducers," IEEE Trans. Ind. Applicat., vol. 28, pp. 1054-1061, Sept. /Oct. 1992

[11] Peng, Z.; Fukao, T.; "Robust speed identification for speed sensorless vector control of induction motors". IEEE Trans. on Ind. Appl. 30 (1994) no. 5, pp. 1234-1240.

[12] J. C. Moreira and T. A. Lipo, "A new method for rotor time constant tuning in indirect field orient control," in IEEE Conf. PESC'90,VA, June 1990, pp. 573580.

[13] Hossam A. Abdel Fattah, Kenneth A. Loparo, Hassan M. Emara, "Induction motor control magnetic system performance under Saturation" Proceedings of the American Control Conference, San Diego, California, 1 June-1999, PP 1668-1672.

[14] E.Levi, S.Vukosavic, V.Vuckovic, "Saturation compensation schemes for vector controlled induction motor drives", IEEE Power Electronics Specialists Conference PESC, San Antonio, TX, 1990, pp. 591-598.

[15] J. E Brown, K. P Kovacs and P. Vas, "A method of including the effect of main flux path saturation in the generalized Equations of Ac machines", IEEE, Trans. Power Appar. and Sys., Vol. PAS 102, no.1, pp. 96-103,1983.

\section{تقييم مقاومة العضو الثابت في التحكم الاتجاهي للمحرك الحثي بدون استخدام حساس لقياس السرعة مع أخذ ظاهرة التثبع المغناطيسي في الاعتبار}

يقدم البحث طريقة لتقييم قيمة مقاومة العضو الثابت للحرك الحثي لاستخدامها في مقيم السرعة للتحكم الأتجاهى للمحرك مع الأخذ في الاعتبار نأثثر ظاهرة التتبع المغناطيسي في الحديد. وتم تقديم

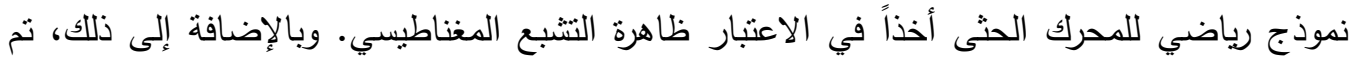

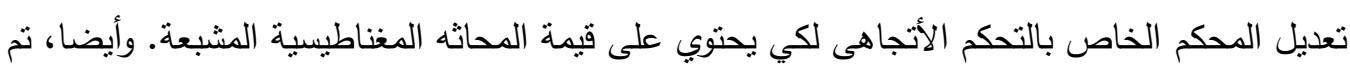
تقديم طريقة فعالة لتقييم السرعة وقيمة مقاومة العضو الثابت للمحرك معتمداً على النموذج المرجعي للنظام الملائم (model reference adaptive system) للحصول على دقة عالية من مقيم السرعة

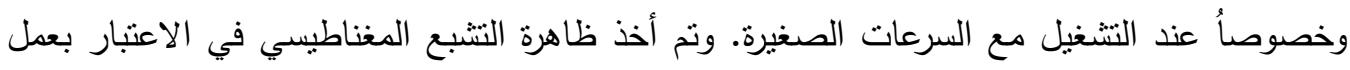
مقدر لقيمة المحاثه المغناطيسية للعمل مع مقيم السرعة للحصول على دقة عالية للتحكم في السرعة في مدى واسع للنتشيل. وتم عرض نتائج باستخدام الحاسوب لنوضيح مدى قدرة الطريقة المقترحة للنطبيق. وقد برهنت النتائج المعروضة على أن خواص نظام المحرك جيدة في الحالة الديناميكية والاستاتيكية وهذا يؤكد قدرة الطريقة على تحقيق الأغراض المطلوبة. 